\title{
Anxiety and Anxiety Disorders in Elite Athletes
}

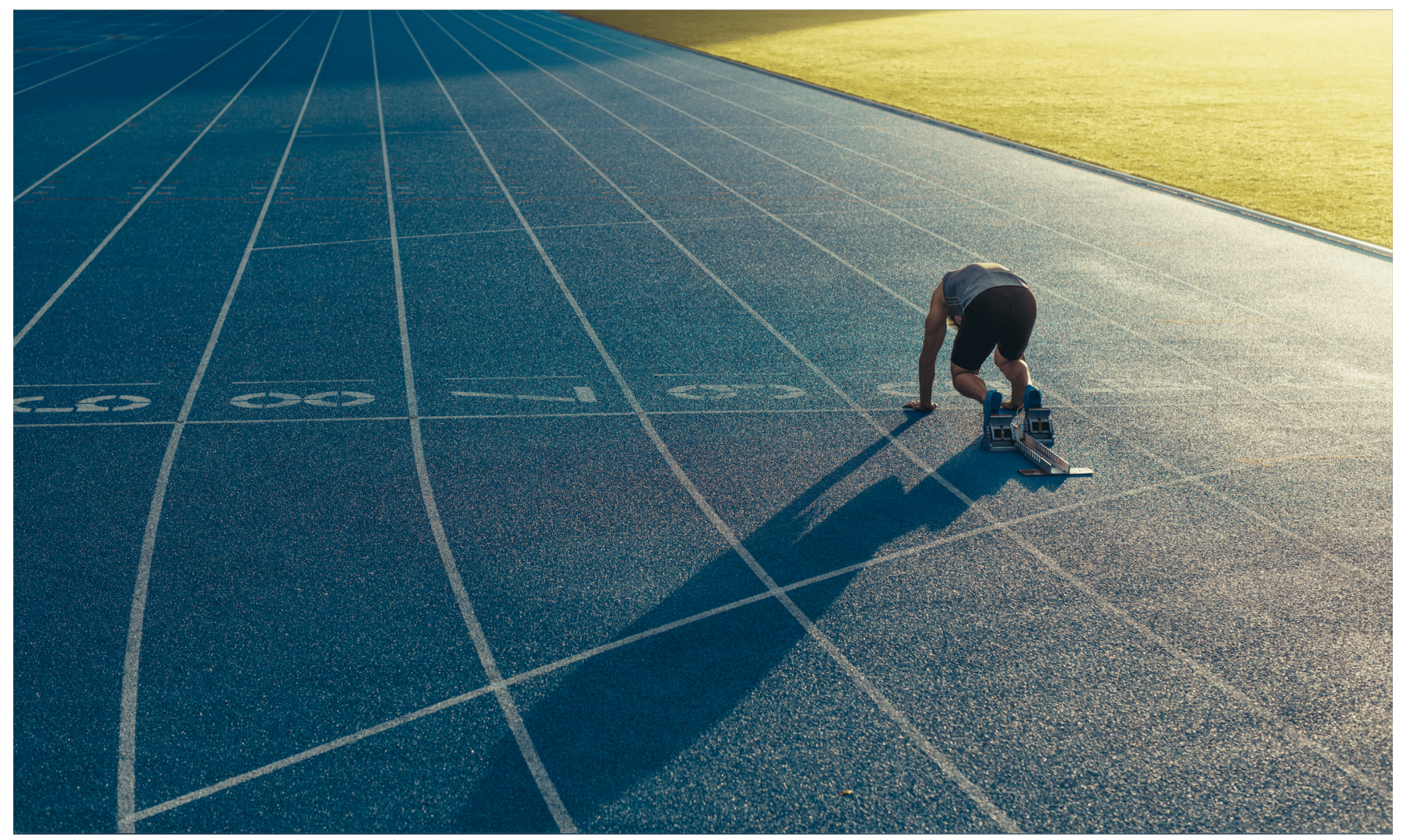

Kranick Daniel $^{1}$, Claussen Malte Christian ${ }^{1,2,3}$, Seifritz Erich $^{1}$, Brühl Annette Beatrix ${ }^{1,4}$

${ }^{1}$ Department of Psychiatry, Psychotherapy and Psychosomatics, University Hospital of Psychiatry Zurich, Zurich, Switzerland

${ }^{2}$ Private Clinic Wyss AG, Münchenbuchsee, Switzerland

${ }^{3}$ Psychiatric Services Grisons, Chur, Switzerland

${ }^{4}$ Centre for Affective, Stress and Sleep Disorders, Psychiatric University Hospital, Basel, Switzerland

“I don't think you're human if you don't get nervous” Sidney Crosby [1].

Anxiety is in principle a normal and (often) helpful emotion in humans and animals. However, anxiety can get excessive and be impairing and disabling. If anxiety is excessive in intensity and duration, occurs in actually non-dangerous situations, uncontrollable, and impairs actions, an anxiety disorder is typically diagnosed [2]. In the general population, the following anxiety disorders are diagnosed (decreasing 
frequency): specific phobias, social anxiety disorders, panic disorder with/without agoraphobia, generalized anxiety disorder [3,4]. In elite athletes the specific subform of performance anxiety disorder could be diagnosed, although it is not yet included in the diagnostic manuals [5,6].

Epidemiological studies in the general population result in anxiety disorders as the most frequent group of mental disorders with a life-time prevalence between 11 and 33\% (depending on the study design) [4]. Epidemiological studies on anxiety disorders in elite athletes are scarce, showing overall no evidence so far that the prevalence would be markedly different from the one in the general population, with potentially even higher rates for generalized anxiety disorder in athletes [7,8,9]. Athletes experience anxiety maybe more frequently than the general population particularly in contests and other test situations where their performance can have longlasting effects. Anxiety is not generally a negative reaction to situations as it can also free up additional resources [1,5,10]. However, too much anxiety and arousal can impair performance by limiting decision making capacities and narrowing focus (inverted U-hypothesis by Yerkes and Dodson) [1,6,11]. This model has been extended by Hanin into the model of the individual zones of optimal functioning (IZOF) where individual variations in elite athletes and the relationship between competitive performance and an individual's optimal range of anxiety are described [1,12,13]. Some athletes prefer a good degree of stress or anxiety prior a competition for optimal performance whereas others will do their best to stay away from additional arousal [13].

If anxiety becomes a problem in an elite athlete this should be detected early, in the same way as in the general population, to prevent development of a chronic course. For diagnosis, the known evaluated instruments for assessing type and severity of the anxiety disorder, as well as differential diagnostic psychiatric assessment to exclude, for instance, other mental disorders such as depression or traumaassociated disorders, should be used. Furthermore, a thorough examination should be done to exclude physical disorders such as hyperthyreosis, asthma bronchiale or other disorders [3,6,14]. Competition anxiety (which occurs not typically in the general population) can be assessed using specific scales [5]. Treatment of anxiety disorders in elite athletes should be done in the same way as in the general population (15), albeit involving besides the athlete also the athlete's team (after developing a communication strategy addressing confidentiality and disclosure with the patient). As a first step, as in the treatment of any anxiety disorder, psychoeducation should include the following point: explanation of the diagnosis, anxiety disorders as frequent and treatable, non-dangerous diagnoses, development and maintenance of anxiety by avoidance behaviours and anticipatory anxiety, relationship of body, emotions, thoughts in anxiety, inverted U-curve of anxiety/arousal and performance [16], and finally general stressand self-management strategies. The specific treatment plan then includes typically more sport-related exercises developed with the coach and the team as well as specific psychotherapy with a focus on individual triggers, physical, emotional and mental reactions and avoidant and/or safety seeking behaviours and subsequent exposure-based therapy. Pharmacotherapy, if indicated should be done according to the respective guidelines using particularly SSRI and SNRI, less commonly tricyclic antidepressants [15,17]. Currently, none of these medications are listed on the WADA Prohibited List (which should however always be checked before prescription) (18). Current research shows that therapists are very hesitant to prescribe these medications despite no evidence of negative (or positive) effects on performance. 


\section{Corresponding author}

Prof. Dr. med. Annette Beatrix Brühl

Centre for Affective, Stress and Sleep Disorders

Psychiatric University Hospital, Basel, Switzerland

annette.bruehl@upk.ch

\section{References}

1. Ford JL, Ildefonso K, Jones ML, Arvinen-Barrow M. Sport-related anxiety: current insights. Open Access J Sports Med. 2017;8:205-12.

2. ICD-10-GM Version 2020, Internationale statistische Klassifikation der Krankheiten und verwandter Gesundheitsprobleme, 10. Revision, German Modification, Version 2020, Mit Aktualisierung vom 01.11.2019, (2019).

3. Weidt S, Brühl A, Delsignore A. My patient is anxious - what's next? Praxis (Bern 1994). 2012;101(8):523-30.

4. Bandelow B, Michaelis S. Epidemiology of anxiety disorders in the 21st century. Dialogues Clin Neurosci. 2015;17(3):327-35.

5. Mellalieu S, Hanton S, Fletcher D. A competitive anxiety review: Recent directions in sport psychology research. 2006. p. 1-77.

6. Patel DR, Omar H, Terry M. Sport-related Performance Anxiety in Young Female Athletes. Journal of Pediatric and Adolescent Gynecology. 2010;23(6):325-35.

7. Schaal K, Tafflet M, Nassif H, Thibault V, Pichard C, Alcotte M, et al. Psychological balance in high level athletes: gender-based differences and sport-specific patterns. PloS one. 2011;6(5):e19007.

8. Gulliver A, Griffiths KM, Mackinnon A, Batterham PJ, Stanimirovic R. The mental health of Australian elite athletes. Journal of science and medicine in sport. 2015;18(3):255-61.

9. Junge A, Prinz B. Depression and anxiety symptoms in 17 teams of female football players including 10 German first league teams. Br J Sports Med. 2019;53(8):471-7.

10. Mahoney MJ, Avener M. Psychology of the elite athlete: An exploratory study. Cognitive Therapy and Research. 1977;1(2):135-41.

11. Yerkes RM, Dodson JD. The relation of strength of stimulus to rapidity of habit-formation. Journal of Comparative Neurology and Psychology. 1908;18(5):459-82.

12. Hänsel F, Baumgärtner SD, Kornmann J, Ennigkeit F. Sportpsychologie. Berlin, Heidelberg: Springer; 2016.

13. Emotions and athletic performance: Individual zones of optimal functioning model, (2007).

14. Bandelow B, Wiltink J, Alpers G, Benecke C, Deckert J, Eckhardt-Henn A, et al. S3-Leitlinie Behandlung von Angststörungen2014 31.12.2019 [cited 2019 31.12.2019]:[275 p.]. Available from:

https://dgppn.de/_Resources/Persistent/0c2fc607fa678377a9efb4f13d5ce7007f2c43d0/S3-LL_Lang_Angs tst\%C3\%B6rungen_2014.pdf.

15. Bandelow B WJ, Alpers G, Benecke C, Deckert J, Eckhardt-Henn A, et al. S3-Leitlinie Behandlung von Angststörungen. 2014.

16. Huttermann S, Memmert D. Does the inverted-U function disappear in expert athletes? An analysis of the attentional behavior under physical exercise of athletes and non-athletes. Physiol Behav. 2014;131:87-92.

17. Bandelow B, Reitt M, Röver C, Michaelis S, Görlich Y, Wedekind D. Efficacy of treatments for anxiety disorders: a meta-analysis. International clinical psychopharmacology. 2015;30(4):183-92.

18. WADA WADA. Prohibited List2020 03.01.2020. Available from: 
https://www.wada-ama.org/sites/default/files/wada_2020_english_prohibited_list_0.pdf. 